Article

\title{
Food Deprivation, Body Weight Loss and Anxiety-Related Behavior in Rats
}

\author{
Silke Dietze ${ }^{1}$, Katarina R. Lees ${ }^{2}$, Heidrun Fink ${ }^{1}$, Jan Brosda ${ }^{1, *}$ and Jörg-Peter Voigt ${ }^{2}$ \\ Received: 24 November 2015; Accepted: 18 December 2015; Published: 7 January 2016 \\ Academic Editors: Marina von Keyserlingk and Clive J. C. Phillips \\ 1 Institute of Pharmacology and Toxicology, School of Veterinary Medicine, Freie Universität Berlin, \\ Koserstr. 20, Berlin 14195, Germany; silke.dietze@fu-berlin.de (S.D.); heidrun.fink@fu-berlin.de (H.F.) \\ 2 School of Veterinary Medicine and Science, University of Nottingham, Sutton Bonington Campus, \\ Loughborough LE12 5RD, UK; katarinalees90@gmail.com (K.R.L.); peter.voigt@nottingham.ac.uk (J.-P.V.) \\ * Correspondence: jan.brosda@fu-berlin.de; Tel.: +49-30-838-53512; Fax: +49-30-838-53112
}

Simple Summary: Food deprivation protocols are frequently used in behavioral studies. However, there is limited evidence as to when food deprivation compromises animal welfare. Regarding the refinement of experiments involving animals, this study investigated the effects of food deprivation on body weight loss and behavior in male and female rats. Sex difference in behavior and motivational state after food deprivation is the main finding of the study. The data highlights the need for tailored pilot experiments to evaluate the impact of food deprivation on animals with regard to the 3Rs principles (replacement, reduction, refinement) in animal science.

\begin{abstract}
In behavioral studies, food deprivation protocols are routinely used to initiate or maintain motivational states that are required in a particular test situation. However, there is limited evidence as to when food deprivation compromises animal welfare. This study investigated the effects of different lengths of food deprivation periods and restricted (fixed-time) feeding on body weight loss as well as anxiety-related and motivated behavior in 5-6 month old male and female Wistar rats. The observed body weight loss was not influenced by sex and ranged between $4 \%$ (16 h deprivation) to approximately $9 \%$ (fixed-time feeding). Despite significant body weight loss in all groups, the motivation to eat under the aversive test conditions of the modified open field test increased only after $48 \mathrm{~h}$ of food deprivation. Long-lasting effects on anxiety as measured in the elevated plus maze test $24 \mathrm{~h}$ after refeeding have not been observed, although fixed-time feeding could possibly lead to a lasting anxiogenic effect in female rats. Overall, female rats showed a more anxiolytic profile in both tests when compared to male rats. Despite these sex differences, results suggest that food deprivation is not always paralleled by an increased motivation to feed in a conflict situation. This is an important finding as it highlights the need for tailored pilot experiments to evaluate the impact of food deprivation protocols on animals in regard to the principles of the 3Rs introduced by Russell and Burch.
\end{abstract}

Keywords: body weight; rat; modified open field; elevated plus maze; food deprivation; welfare

\section{Introduction}

Russell and Burch's 3R principle-Replacement, Reduction and Refinement-has become increasingly important in designing and conducting animal experiments [1-3]. Food and water restriction and deprivation procedures are an essential part of many protocols in behavioral neuroscience. These include protocols for appetitive learning, conflict procedures, impulse control, but also the study of feeding behavior itself [4-9]. Whereas in behavioral studies food restriction procedures are often being used to change motivational states, toxicity studies or preclinical acute drug 
screening tests require fasting in order to exclude an effect on diet-dependent substance bioavailability and absorption [10-12]. Considering the widespread use of food deprivation procedures in animal research, relatively little systematic studies have been conducted as to what extent these procedures interfere with animal welfare. Fasting in rodents is accompanied with body weight loss, and loss of body weight is regarded as a surrogate parameter for welfare. Food deprivation periods of $24 \mathrm{~h}$ and $48 \mathrm{~h}$ are the most frequently used protocols [13], and a $48 \mathrm{~h}$ fast can lead to up to $20 \%$ body weight loss [14]. A $20 \%$ loss of body weight is regarded as critical and has been defined as one of the humane endpoints in several international guidelines [15-17]. The guidelines set by the European Parliament (Directive 2010/63/EU [18]) state a severity classification of procedures in laboratory animals. The severity of a food deprivation period of $24 \mathrm{~h}$ in rats is defined as "mild", and $48 \mathrm{~h}$ of food deprivation is defined as "moderate". Yet, this grading has not been sufficiently verified by corresponding experimental data. Still, it has to be considered that restriction schedules may improve longevity $[19,20]$. However, food deprivation or restriction is associated with increasing metabolic and psychological stress, e.g., animals may experience chronic hunger [19,21].

The first aim of this study was to assess the maximum body weight loss in rats following 16, 24 and $48 \mathrm{~h}$ fasts. In addition, restricted feeding, i.e., providing either less food or a shorter time when food was available, was also included in this part of the study. Restricted feeding is mostly used in long-term experimental studies, e.g., operant conditioning procedures [22] or in toxicity studies [10]. Generally, a positive correlation between the duration of fasting and the response rate is assumed [23]. To our knowledge, only a few studies have looked into the effects of restricted feeding on species-specific unconditioned behavior [22,24]. Heiderstadt et al., (2000) fed rats at a level to maintain a $20 \%$ reduction of their initial body weight and found increased activity in an open field test alongside increased serum corticosterone levels as measured 37 days after the start of the experimental period [22].

The issue of using severe food deprivation in experimental situations, in particular conditioning, has already been discussed in the past [25]. Moran, (1975) brings forward the argument that severe food deprivation could change the motivational state to an extent that it would interfere with species-specific behaviors and thus with multiple variables during conditioning [25]. Such motivational changes could therefore become a confounding variable in behavioral testing, e.g., in protocols of learning and memory testing. This applies in particular to experimental situations where subjects are food deprived and food items are being used as reward.

Therefore, a second aim of the present study was to investigate effects of food motivation in a conflict situation, which does not include conditioning and thus reduces the number of variables. To this end, we used an experimental set up based on the conflict between neophobia/anxiety and hunger [26]. Our aim was to investigate the relationship between the duration of fasting and the motivation of an animal to overcome a potentially aversive situation for the benefit of getting food. For balancing the anxiety of the rat against the motivation of hunger a modified open field (mOF) test [27], also known as novelty induced hypophagia (NIH) test [28,29], was used. The mOF was extensively validated in our laboratory and represents a conflict model, which is a valid measure of anxiety-related behavior as anxiolytic drugs stimulate food intake in such an aversive situation [27].

To investigate possible long lasting effects on emotional states of the animals, we exposed rats to the elevated plus maze (EPM) test of anxiety-related behavior. The EPM test is a subtle and commonly used test to assess anxiety-related and exploratory behavior in rodents [30]. The test has been extensively validated and evaluated [31-34]. It has been demonstrated that preceding stress has a significant impact on measures of anxiety-related behavior in this test [35-37], which makes it a robust animal model of state anxiety [36,38].

We hypothesize that food deprivation will lead to a significant reduction in body weight, accompanied by reduced anxiety-related behavior in the mOF test, i.e., an increased motivation to feed in an aversive environment. The magnitude of behavioral effects should correlate with the duration of food deprivation. 
The results of the study on hand may help to gain new insights for the refinement of various feeding protocols in laboratory animals, which will consequently reduce stress in the animals and enhance their wellbeing during housing and in the experimental setting.

\section{Experimental Section}

\subsection{Animals}

The experiments were performed in accordance with the guidelines of the German Animal Protection Law and had been approved by the Berlin State Authority ("Landesamt für Gesundheit und Soziales" (LaGeSo); G 0153/12). The ethical acceptability of the animal experiments is a crucial part of the application, which was discussed with the Animal Welfare Officer of the Freie Universität Berlin and subsequently reviewed by an ethical commission assisting the LaGeSo Berlin. The potential of implementing the concept of the 3Rs was rigorously researched during each part of the present study. All experimenters involved were well trained and experienced in the use of laboratory animals and their behavior.

A total of 51 naive male $(n=25 ; \varnothing 440 \mathrm{~g} \pm 30 \mathrm{~g})$ and female $(n=26 ; \varnothing 260 \mathrm{~g} \pm 16 \mathrm{~g})$ Wistar rats (Harlan Laboratories, Horst, the Netherlands) aged 5-6 months were used. Prior to the experiments, the animals were group-housed $(n=2-4)$ in type IV Macrolon cages $(59 \times 38 \times 20 \mathrm{~cm}$, floor area $1.815 \mathrm{~cm}^{2}$; Ehret, Wandlitz, Germany) with dust-free hardwood bedding (Hygienic Animal Bedding, J. Rettenmaier \& Söhne GmbH und Co. KG, Rosenberg, Germany) under standard conditions (room temperature $22 \pm 2{ }^{\circ} \mathrm{C}$; relative humidity $55 \% \pm 10 \%$ ) on a $12 \mathrm{~h}$ light/dark schedule (lights on at 6:00 am). Home cages were enriched by paper tissues and metal tubes as hiding places. Before and during experiments the rats received the standard lab chow to which they were accustomed (V153x R/MH: $19 \%$ protein, 3.3\% fat, $4.9 \%$ fiber, $6.4 \%$ ash, trace elements, and vitamins; ssniff, Soest, Germany) and tap water, and were handled and weighed every other day. Once weekly, the home cages were cleaned and equipped with new bedding by a professional animal keeper. Animals were free of pathogens according to Federation for Laboratory Animal Science (FELASA) recommendations and their health status was monitored quarterly.

\subsection{Experimental Design}

\subsubsection{Food Deprivation and Fixed-Time Feeding Schedule}

After an initial body weight measurement, which allowed us to exclude any significant outliers, the animals were randomly allocated to the five independent experimental groups of $16 \mathrm{~h}, 24 \mathrm{~h}, 48 \mathrm{~h}$ of food deprivation (no access to food), 4 days of food restriction (fixed-time feeding; FF), or ad libitum feeding (control group). Sixteen hours before starting the experiments, the rats were transferred to single-housing (Macrolon cages type III; habituation period) enriched by metal tubes as hiding places. In the fixed-time feeding group, animals received food for $4 \mathrm{~h}$ daily (8:00-12:00 am) for four consecutive days [27]. The ad libitum fed control group underwent the same handling procedures (e.g., single housing, body weight measurement). Water was freely available at all times. With the exception of the control group (five males, six females), each group consisted of five males and five females. Group sizes were calculated by G*Power 3 (Heinrich-Heine-Universität Düsseldorf, Düsseldorf, Germany) [39].

\subsubsection{Body Weight Measures}

Body weight in relation to $\mathrm{mOF}$ testing was measured immediately before the food deprivation commenced and following the $5 \mathrm{~min}$ exposure to the test, i.e., before refeeding. Body weight before fasting or fixed-time feeding was set at $100 \%$ for each animal and their body weight at the time of mOF was then compared to this. 


\subsubsection{Behavioral Experiments}

All experiments were conducted in a sound-attenuated room between 8:30-12:30 am. Animals were habituated to the room for $1 \mathrm{~h}$ before starting the respective experiment. The behavior of each rat was recorded and analyzed using a computer-based tracking system (VideoMot 2; TSE-Systems, Bad Homburg, Germany). Testing arenas were cleaned with Meliseptol ${ }^{\circledR}$ between each animal. The timing of food deprivation periods was staggered, to ensure that animals of the individual experimental groups had fasted for the same time at the beginning of the behavioral testing, which was performed during the last hour of food deprivation.

\subsubsection{Modified Open Field (mOF) Test}

The mOF test was performed as described by Rex et al., (1998) [8]. Briefly, the rats were individually placed in one corner of a brightly illuminated (350 lux) white open field $(100 \times 100 \times 40 \mathrm{~cm})$ facing the center of the open field, in which familiar food pellets (standard chow) were available. The rats were observed for $5 \mathrm{~min}$ and their behavior was analyzed for the following parameters: incidence of food intake (\% of rats feeding per group), latency to initial food contact (s), distance traveled ( $\mathrm{cm}$, horizontal locomotion), and number of rearings (vertical activity). At the end of each experiment, animals were returned to their home cages and to ad libitum feeding.

\subsubsection{Elevated Plus Maze (EPM) Test}

Twenty-four hours after completion of the mOF experiment and refeeding, the animals were tested for anxiety-related behavior using an EPM. The maze consisted of two open arms $(50 \times 15 \mathrm{~cm})$ and two enclosed arms $(50 \times 15 \times 10 \mathrm{~cm})$, which were connected by a central platform $(15 \times 15 \mathrm{~cm}$; height of the maze: $64 \mathrm{~cm}$ ). Illumination was 250 lux on the surface of the open arms, 60 lux in the closed arms and 200 lux on the central platform. The rats were placed on the central platform facing the corner between open and closed arm, allowing equal opportunity of entering one of these arms. Each animal was observed for $5 \mathrm{~min}$. As classical parameters related to anxiety behavior, the number of entries into the open arms in relation to total entries, and the time spent in the open arms (s) were recorded. In addition, the total distance traveled $(\mathrm{cm})$ and number of rearings were measured (these parameters are not independent from anxiety in the EPM). The number of head dips was monitored as a parameter of risk assessment.

\subsubsection{Data Presentation and Analysis}

Data was analyzed and presented using SigmaPlot 11 software (Systat Software, Erkrath, Germany). Body weight data was analyzed by Student's paired t-tests. A Fisher's exact test was used to evaluate the incidence of food intake in the $\mathrm{mOF}$ and an alpha adjustment was applied for multiple comparisons to the control group. All other behavioral data (mOF and EPM) was analyzed by two-way ANOVA (sex, feeding condition) followed by post hoc analysis using the Holm-Sidak method. $p<0.05$ was considered statistically significant. Data is presented as mean values plus standard error of the means (S.E.M.).

\section{Results}

\subsection{Effect of Food Deprivation and Fixed-Time Feeding Schedule on Body Weight Change}

Food deprivation led to a decrease in body weight in both male and female rats. The animals' weight loss increased with the duration of fasting and was greatest under fixed-time feeding conditions. The effects varied between a 3.6\% $(p<0.001$, males $)$ and 5.3\% $(p<0.004$, females $)$ after $16 \mathrm{~h}$ of deprivation up to a $6.1 \%$ reduction $(p<0.003$ males) or $8.2 \%$ ( $p<0.001$, females) after $48 \mathrm{~h}$. The most pronounced weight loss occurred after the fixed-time feeding schedule. Four daily feeding periods lasting 4 h each induced body weight losses of $8.7 \%$ in male and $9.4 \%$ in female rats $(p<0.001$; Figure 1$)$. 
Two-way ANOVA did not reveal any sex effect on body weight change during food deprivation. There were negligible body weight changes in the control groups during the experimental period $(+0.46 \%$ in males, $+0.73 \%$ in females).

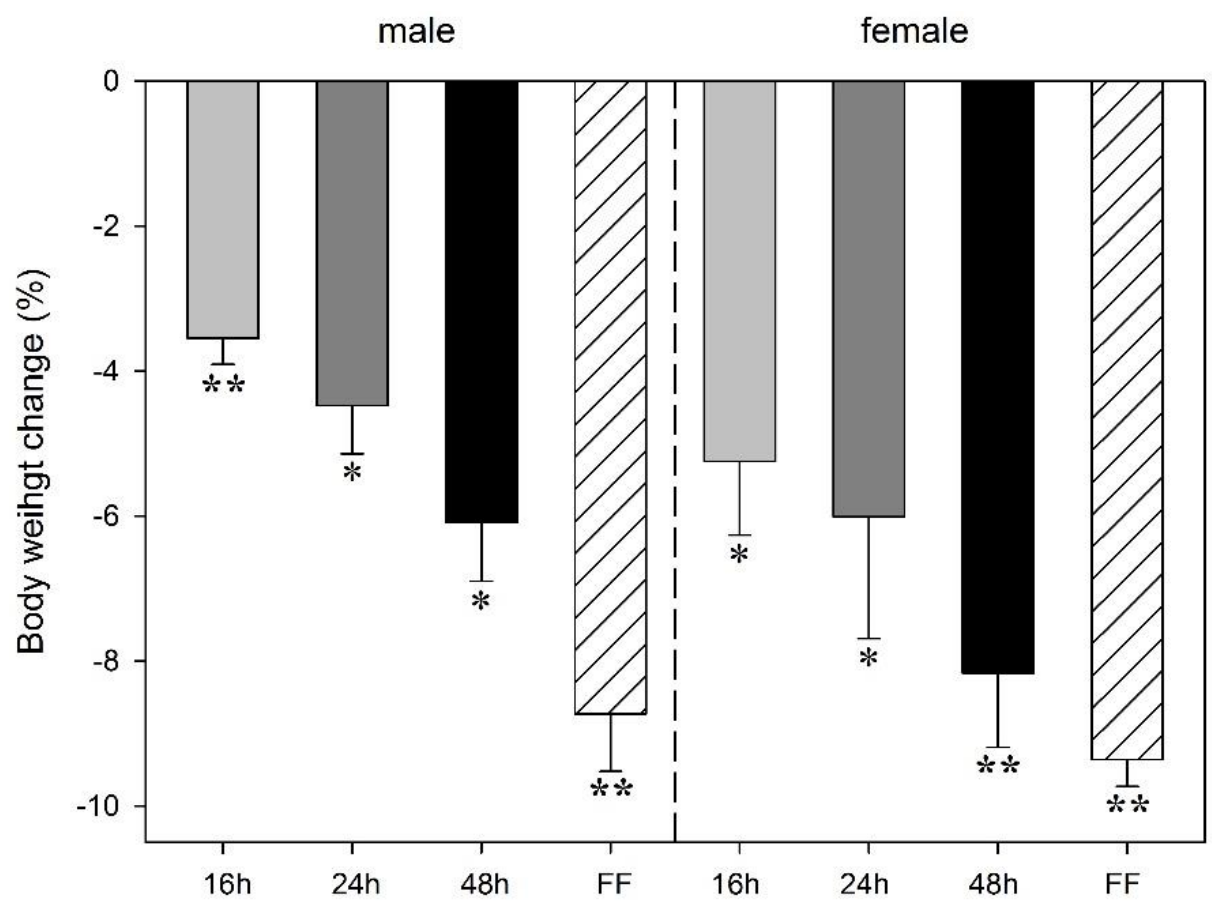

Figure 1. Effect of food deprivation ( $16 \mathrm{~h}, 24 \mathrm{~h}, 48 \mathrm{~h}$ ) or fixed-time feeding schedule (FF; $4 \mathrm{~h}$ for 4 days) on body weight change in male and female rats. Expressed are the mean body weight changes (\%) in relation to animal body weights at the onset of deprivation period or food restriction. Data is mean -S.E.M. ${ }^{*} p<0.05 ;{ }^{* *} p<0.001$ before $v$ s. after food deprivation.

\subsection{Effect of Food Deprivation and Fixed-Time Feeding Schedule on the Performance in the mOF Test}

As the impact of deprivation on body weight was not sex-specific, the incidence of food intake in the mOF was analyzed for males and females together. While $16 \mathrm{~h}$ and $24 \mathrm{~h}$ fasts (one out of 10 animals $(10 \%)$ each) as well as a fixed-time feeding schedule $(2 / 10(20 \%))$ showed no effect on the rats' incidence to eat when compared to controls $(0 / 11(0 \%))$, a $48 \mathrm{~h}$ fast significantly increased the number of rats feeding in the arena to $(5 / 10(50 \%))$; as compared to controls $(p<0.05$; Figure 2$)$. No differences in the latency to start feeding were observed.

In male or female rats, the length of food deprivation had no effect on the distance traveled. However, an interaction between sex and deprivation period $\left(\mathrm{F}_{4,40}=2.89, p=0.035\right)$ and a significant main effect of sex $\left(\mathrm{F}_{1,40}=17.65, p<0.001\right)$ were found with females rats traveling a longer distance in the mOF (Figure 3). Food deprivation had no effect on rearings. One female rat of the FF group was excluded from the analysis because of malfunction of the tracking software. 


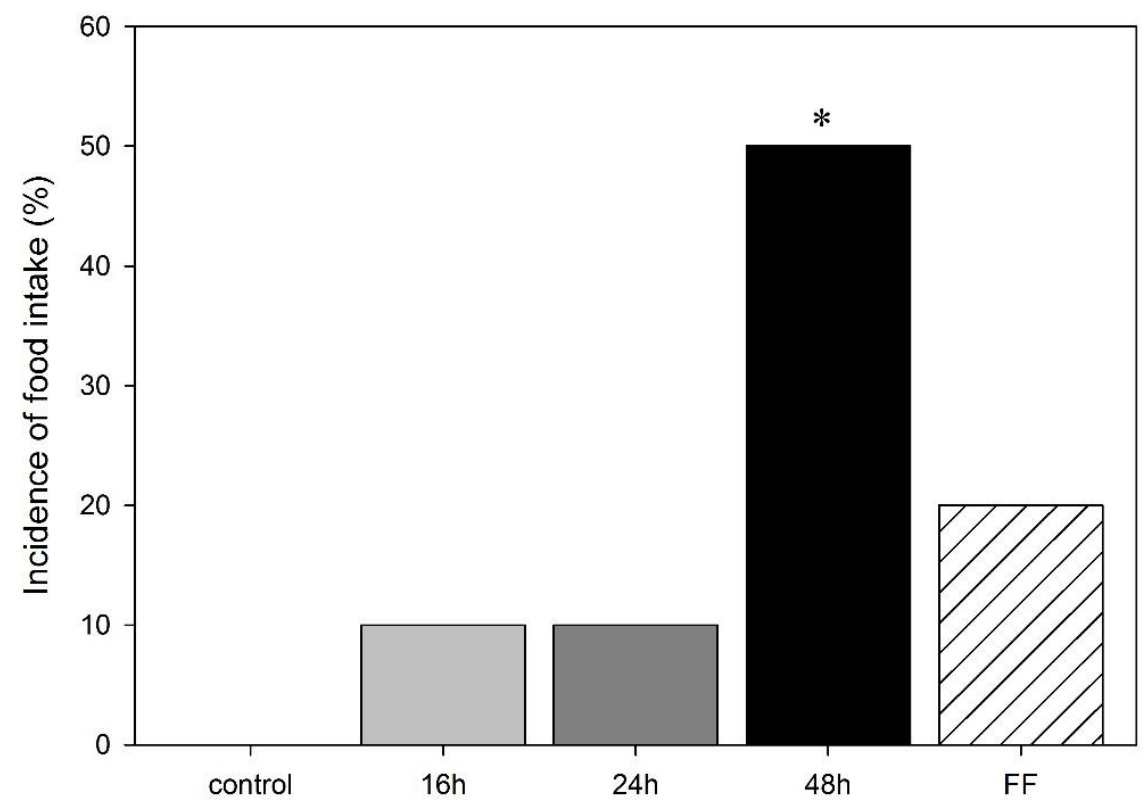

Figure 2. Percentage of rats feeding in the modified open field test in male and female rats following food deprivation ( $16 \mathrm{~h}, 24 \mathrm{~h}, 48 \mathrm{~h}$ ), fixed-time feeding schedule (FF; $4 \mathrm{~h}$ for 4 days) or free feeding (control). Data is mean, ${ }^{*} p<0.05$ vs. control.

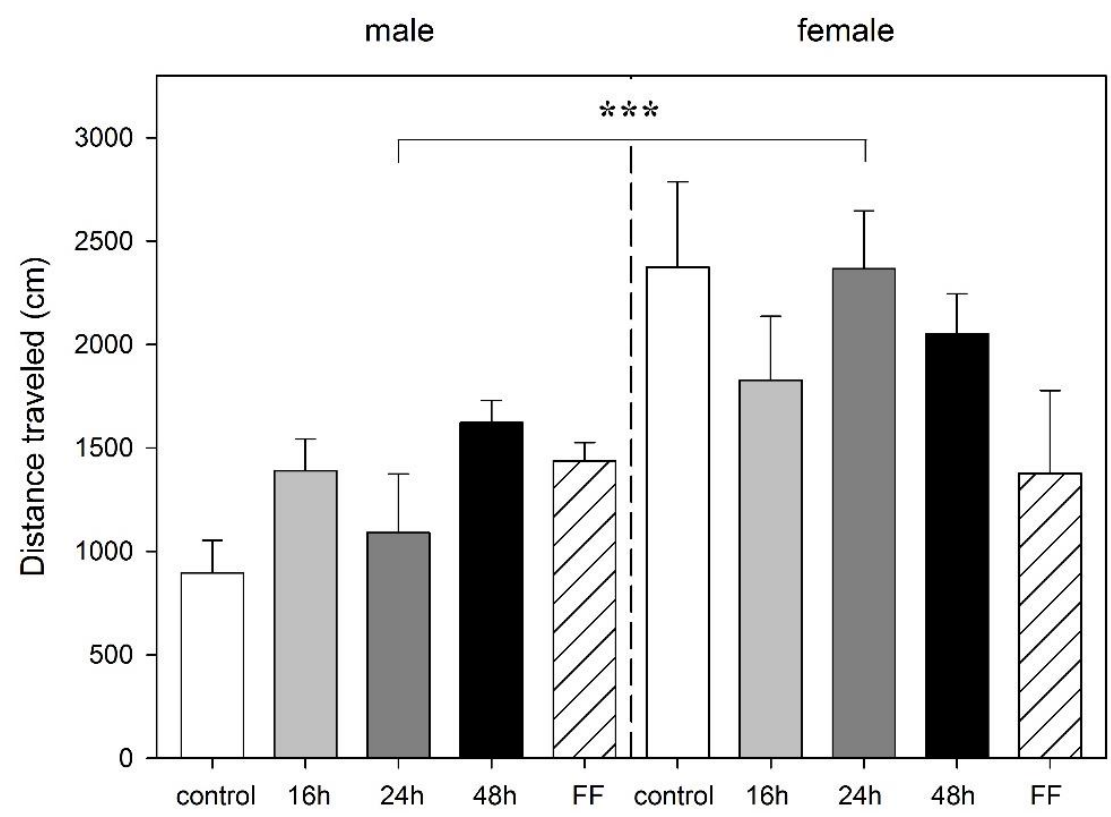

Figure 3. Effect of food deprivation ( $16 \mathrm{~h}, 24 \mathrm{~h}, 48 \mathrm{~h}$ ), fixed-time feeding schedule (FF; $4 \mathrm{~h}$ for 4 days) or free-feeding (control) on spontaneous activity in the modified open field test in male and female rats. Data is mean +S.E.M. Two-way ANOVA showed sex significance, ${ }^{* *} p<0.001$, but no food deprivation significance.

\subsection{Effect of Food Deprivation and Fixed-Time Feeding Schedule on the Performance in the EPM Test}

Twenty-four hours following mOF exposure and returning to ad libitum feeding, all rats were tested in the EPM. None of the preceding food deprivation schedules had an impact on anxiety-related behavior in the EPM when rats were exposed to the test following the refeeding period (Figure 4). However, a significant main effect of sex on anxiety-related parameter entries and time spent in open arms (entries (\%): $\mathrm{F}_{1,41}=7.32, p=0.01$; time $\left.(\mathrm{s}): \mathrm{F}_{1,41}=10.23, p=0.003\right)$ was found. Females showed an 
increase in these parameters, i.e., they visited the aversive arms more frequently, suggesting anxiolytic behavior (Figure 4a,b). Although there was no overall effect of feeding on the EPM behavior, female rats, previously exposed to fixed-time feeding, showed a tendency to significance for spending less time on the aversive open arms ( $p=0.083$ ) (Figure $4 b)$.

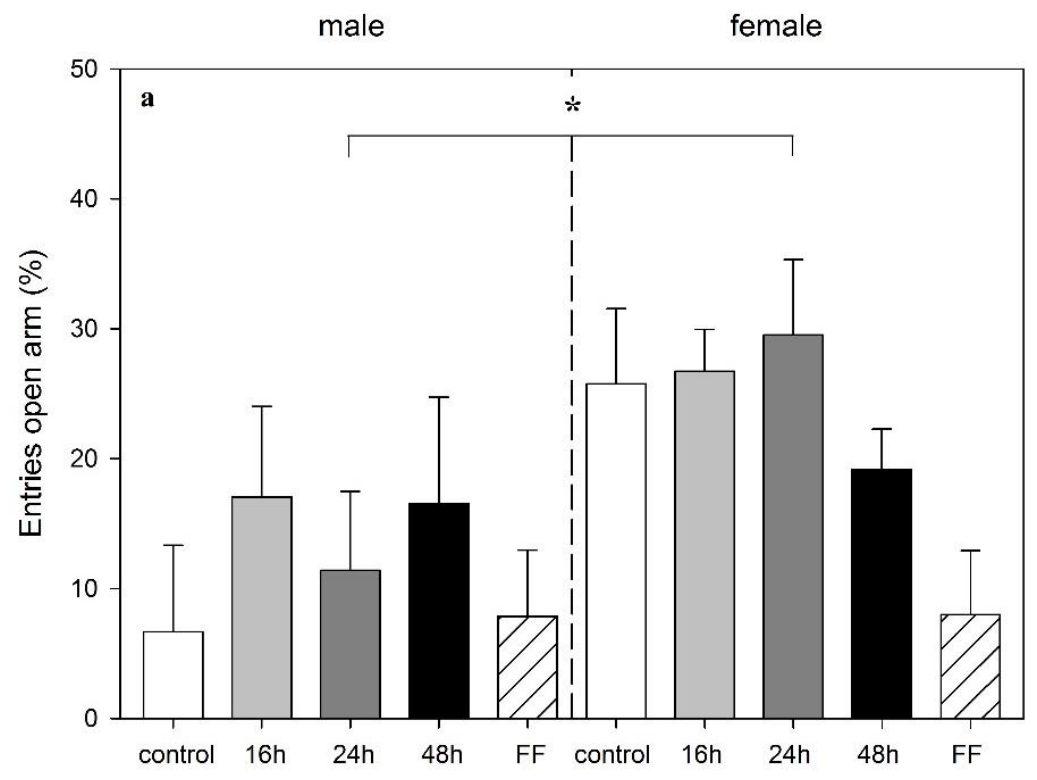

(a)

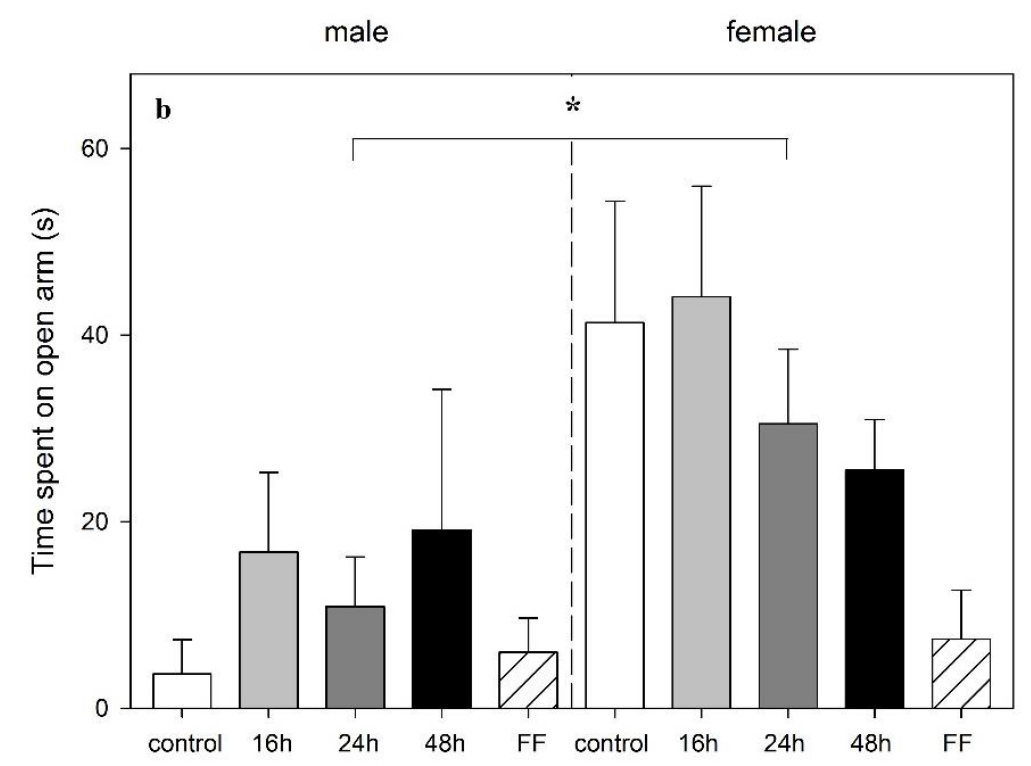

(b)

Figure 4. Cont. 


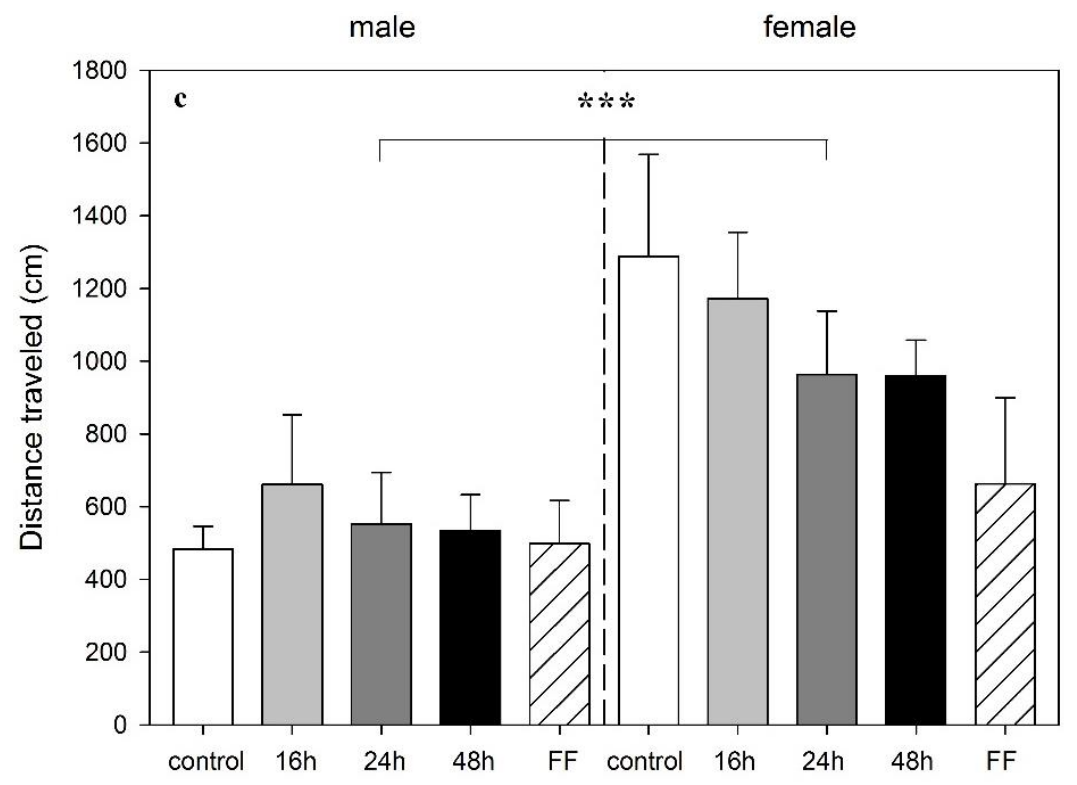

(c)

Figure 4. Effect of food deprivation ( $16 \mathrm{~h}, 24 \mathrm{~h}, 48 \mathrm{~h}$ ), fixed-time feeding schedule (FF; $4 \mathrm{~h}$ for 4 days) or free-feeding (control) on the performance in the elevated plus maze test in male and female rats. (a) Percentage of open arm entries; (b) time in open arms; and (c) distance traveled are shown. Data is mean +S.E.M. Two-way ANOVA showed sex significance, (A and B: ${ }^{*} p<0.05$; C: ${ }^{* *} p<0.001$ ) but no food deprivation significance.

As in the $\mathrm{mOF}$, females traveled a longer distance in the EPM when compared to males $\left(F_{1,41}=16.89, p<0.001\right)$ (Figure 4c). Food deprivation had no effect on rearings or head dips in this test.

\section{Discussion}

In this study, body weight changes resulting from food deprivation and food restriction and subsequent behavioral changes have been assessed in rats. There are currently a limited number of studies analyzing these parameters together, and therefore the present study aims at providing a more comprehensive view on the effects of food deprivation and food restriction in the rat. The main finding is that food deprivation and a fixed-time feeding caused a significant and sex-independent loss in body weight, but only a $48 \mathrm{~h}$ food deprivation had a measurable effect during behavioral testing. This finding was not expected because deprivation periods in the range of $16 \mathrm{~h}$ and $48 \mathrm{~h}$ are widely used in behavioral studies [13].

The average $8 \%$ weight loss (the observed maximum was $13 \%$ in a single rat) following the $48 \mathrm{~h}$ deprivation period as reported here is in keeping with previous reports [40-42]. However, others have reported a higher average weight loss of $15 \%$ in Wistar rats following only $24 \mathrm{~h}$ of deprivation [43]. In other rat strains, even higher reductions up to $18 \%$, have been reported following a $24 \mathrm{~h}$ fast [44-47]. Thus, strain and substrains that may exist in various laboratories could be a variable that contributes to the extent of body weight loss following food deprivation. Regarding the moderate weight loss seen in the present study, compensatory water consumption can be excluded, as various studies have shown that body weight decrease during deprivation periods of 3 and 4 days is paralleled by a decreased water intake [41,48]. Another variable could be the age of the animal, with younger rats losing a higher percentage of body weight than older rats. The evidence for this comes from a study by Li and Wassner [49], where younger rats lost $29 \%$ body weight following $24 \mathrm{~h}$ of food deprivation. 
Therefore, we suggest performing pilot studies to ensure that weight loss does not exceed the permitted weight loss limit imposed by the regulatory body and/or animal ethics committee to prevent undue suffering to the animals.

A strong effect on body weight could also be indicative of a severely unbalanced motivational state, which could add a stochastic element to behavioral testing and compromise the interpretation of behavioral data [25]. This aspect was approached with the behavioral part of the present study, where we tried to establish the length of a deprivation period that would be required to increase the motivation of a rat in a conflict situation and whether a mild fixed-time feeding regimen would also be suitable to generate this motivation. Therefore, the mOF test was used in the present study. This test is based on the interplay between the rats' motivation to feed, as manipulated by food deprivation or restriction, and anxiety, induced by exposure the aversive open field [27]. By increasing the time of food deprivation, the test allows us to identify the threshold where the motivation to feed overrides the anxiety-induced protective behavior as expressed by the avoidance of the center of the arena where the food has been placed. Surprisingly, this threshold was not reached with fasts shorter than $48 \mathrm{~h}$ where $50 \%$ of the rats went to the center and started to eat. Based on previous results [27], we expected to find this threshold at a rather shorter deprivation period. Various factors could account for the discrepancy of these studies, including the averseness to the test arena, the novelty of the presented food items, age of the animals, or the substrain of rats that were used. As discussed before, age could contribute to the relatively small weight loss following food deprivation and hence a reduced motivation to feed. The averseness to the present test conditions was not different compared to Rex et al., (1998), and the presented chow was familiar to the rats, whereas in other versions of this test novel food had been presented [50,51]. Previous studies in our lab demonstrated that between $10 \%$ and $100 \%$ of rats from various strains started feeding following $20 \mathrm{~h}$ of deprivation [27,52,53]. Moreover, substrains of Wistar rats differ considerably in their food intake after a $20 \mathrm{~h}$ deprivation [53].

The present study suggests that despite a significant loss of body weight, the motivation to feed under anxiogenic conditions requires a certain level of body weight loss. A discussion of our findings in the context of previous studies, both from our lab and from other groups, revealed that this level seems to depend on a variety of factors. Hence, customized pilot studies are recommended assessing which level of body weight loss actually impacts on the motivational state in a given experimental situation. This could also minimize detrimental interferences due to "overdeprivation" with motivational states as for example during conditioning experiments. The outcome of these pilot studies could actually improve the welfare of the rats by the avoidance of unnecessarily long fasting periods.

In the fixed-time feeding group, rats lost more body weight than the $48 \mathrm{~h}$ fasted rats. However, in contrast to food deprivation, four days of fixed-time feeding did not affect feeding in the mOF. Although in the current study the weight loss was the highest in this group, it was still lower compared to studies where behavioral effects have been reported [54,55]. The lack of correlation between weight loss and behavior in the mOF indicates that weight loss per se is not a good indicator of the motivational and/or emotional state of the rat. Unlike our results, Inoue et al., (2004) could demonstrate a reduction of anxiety tested on the EPM in Wistar rats after restricted feeding [54]. However, with only $2 \mathrm{~h}$ daily feeding time, their food restriction regime was more stringent than ours. Similarly, food restriction for 7 days maintaining $85 \%$ of the body weight resulted in an anxiolytic effect in male Lister Hooded rats [55]. In another study, male rats maintained at $80 \%$ of their initial body weight made more entries into the aversive inner zone of an open field, which could be interpreted as an anxiolytic effect. Only repeated exposure to the test arena revealed increased locomotor activity in these rats [22]. However, in the light of increased serum corticosterone levels in these rats, the interpretation of the behavioral data is not straightforward, because high levels of stress hormones are usually associated with increased anxiety [56]. Fixed-time feeding initiates a cascade of neurobiological and metabolic events, which can prevent obesity in rodents [57]. Restricted feeding, in particular fixed-time feeding, has multiple effects on a variety of physiological and behavioral systems which include the entrainment of circadian rhythms and adjustments in plasma corticosterone levels in anticipation to feeding [58,59]. Fixed-time 
feeding causes adaptations in the CNS that include circadian oscillators [60], but these adaptations are not confined to one brain structure and are more evident in the thalamus, hippocampus and hypothalamus [61]. One would expect that these neural adaptations, although likely to emerge early on in rats, would develop over time. Hence a gradual initiation of the procedure ("training") could possibly have a stress-reducing effect. However, revealing time pattern and plasticity of fixed-time feeding-induced neural and behavioral changes requires further investigation.

The third part of our study was aimed to answer the question whether in refed rats the experience of a previous period of food deprivation or restriction could lead to lasting behavioral consequences. Physiological changes occur during and after a food deprivation period, especially during the refeeding period [41]. Moreover, food deprivation is a potential stressful event. Thus, acute deprivation for $24 \mathrm{~h}$, but not for 6 and $16 \mathrm{~h}$, has been reported to induce an elevation of plasma corticosterone levels in Sprague Dawley rats [62]. Not only acute food deprivation but also chronic restriction have an impact on several plasma hormone levels, with an increase of corticosterone in Wistar rats and in other rat strains $[19,63]$, although contrasting findings suggests that a significant corticosterone increase in Wistar rats does not occur before at least 5 days of food deprivation $[64,65]$.

In our study, only the female fixed-time fed group showed possibly lasting behavioral effects following refeeding as expressed by a tendency of anxiety related behavior in the EPM. Such an effect, if true, would contradict previous findings where exposure of female Sprague-Dawley rats to cycles of caloric restriction followed by refeeding did not influence anxiety related behavior [66]. However, the present study cannot rule out any long lasting behavioral effects, in particular in behaviors not directly related to anxiety, as those have not been investigated here.

The observed overall anxiolytic behavior in females on the EPM is in keeping with previous studies [67-69]. Despite the sex effect on locomotor activity, which is possibly not independent from anxiolysis at least in the EPM [32], food deprivation and restriction per se had no impact on the locomotor activity in the respective test groups. This coincides with earlier findings [70], demonstrating in Sherman rats that locomotor activity was not affected by food deprivation whereas other forms of exploratory behavior increased. Similarly in Long-Evans rats, food deprivation did not affect locomotor activity [71].

In further studies on the subject, systematic alteration of experimental variables, e.g., various degrees of deprivation $v s$. various degrees of averseness should be performed. Concomitant measures of stress hormones, but also analysis of home cage behavior might help to further substantiate the effect of various feeding and deprivation schedules on welfare.

\section{Conclusions}

In conclusion, our results could help to improve animal welfare by the refinement of study designs, which involve food restriction or deprivation of experimental animals. The data suggests that weight loss and motivation to feed are not strongly correlated. Our results are in favor of pilot studies to ensure good welfare during the actual behavioral experiments.

Acknowledgments: The authors thank Sabine Jacobs for her excellent technical assistance and Wiebke Gentner for proof reading the manuscript.

Author Contributions: Participated in research design: Silke Dietze and Jörg-Peter Voigt. Conducted experiments: Silke Dietze and Katarina R. Lees. Performed data analysis: Silke Dietze and Katarina R. Lees. Wrote or contributed to the writing of the manuscript: Jan Brosda, Silke Dietze, Heidrun Fink and Jörg-Peter Voigt.

Conflicts of Interest: The authors declare no conflict of interest.

\section{References}

1. Russell, W.M.S.; Burch, L.R. The Principles of Humane Experimental Technique. In The Principles of Humane Experimental Technique; Methuen \& Co.: London, UK, 1959. 
2. Burden, N.; Chapman, K.; Sewell, F.; Robinson, V. Pioneering better science through the 3Rs: An introduction to the national centre for the replacement, refinement, and reduction of animals in research (NC3Rs). J. Am. Assoc. Lab. Anim. Sci. 2015, 54, 198-208. [PubMed]

3. Baumans, V. Use of animals in experimental research: An ethical dilemma? Gene Ther. 2004, 11, 64-66. [CrossRef] [PubMed]

4. Bert, B.; Harms, S.; Langen, B.; Fink, H. Clomipramine and selegiline: Do they influence impulse control? J. Vet. Pharmacol. Ther. 2006, 29, 41-47. [CrossRef] [PubMed]

5. Carlini, V.P.; Martini, A.C.; Schioth, H.B.; Ruiz, R.D.; Fiol de Cuneo, M.; de Barioglio, S.R. Decreased memory for novel object recognition in chronically food-restricted mice is reversed by acute ghrelin administration. Neuroscience 2008, 153, 929-934. [CrossRef] [PubMed]

6. Conrad, C.D. A critical review of chronic stress effects on spatial learning and memory. Prog. Neuropsychopharmacol. Biol. Psychiatry 2010, 34, 742-755. [CrossRef] [PubMed]

7. Kant, G.J.; Yen, M.H.; D'Angelo, P.C.; Brown, A.J.; Eggleston, T. Maze performance: A direct comparison of food vs. water mazes. Pharmacol. Biochem. Behav. 1988, 31, 487-491. [CrossRef]

8. Voigt, J.P.; Huston, J.P.; Voits, M.; Fink, H. Effects of cholecystokinin octapeptide (CCK-8) on food intake in adult and aged rats under different feeding conditions. Peptides 1996, 17, 1313-1315. [CrossRef]

9. Buresova, O.; Bures, J. Learning and memory. In Techniques and Basic Experiments for the Study of Brain and Behavior; Elsevier: Amsterdam, The Netherlands, 1983; pp. 135-216.

10. Moriyama, T.; Miyazawa, H.; Tomohiro, M.; Fujikake, N.; Samura, K.; Nishikibe, M. Beneficial effect of moderate food restriction in toxicity studies in rats. J. Toxicol. Sci. 2006, 31, 197-206. [CrossRef] [PubMed]

11. Keenan, K.P.; Laroque, P.; Dixit, R. Need for dietary control by caloric restriction in rodent toxicology and carcinogenicity studies. J. Toxicol. Environ. Health B Crit. Rev. 1998, 1, 135-148. [CrossRef] [PubMed]

12. Sharma, S.; Hryhorczuk, C.; Fulton, S. Progressive-ratio responding for palatable high-fat and high-sugar food in mice. J. Vis. Exp. 2012. [CrossRef] [PubMed]

13. Claassen, V. Neglected Factors in Pharmacology and Neuroscience Research: Biopharmaceutics, Animal Characteristics, Maintenance, Testing Conditions; Elsevier: Amsterdam, The Netherlands, 1994.

14. Garlick, P.J.; Millward, D.J.; James, W.P. The diurnal response of muscle and liver protein synthesis in vivo in meal-fed rats. Biochem. J. 1973, 136, 935-945. [CrossRef] [PubMed]

15. CCAC. Guidelines on: Choosing an Appropriate Endpoint in Experiments Using Animals for Research, Teaching and Testing. 1998. Available online: http://www.ccac.ca/Documents/Standards/ Guidelines/Appropriate_endpoint.pdf (accessed on 24 November 2015).

16. OECD. Guidance Document on the Recognition, Assessment, and Use of Clinical Signs as Humane Endpoints for Experimental Animals Used in Safety Evaluation, 2000. Available online: http://www.oecd.org/officialdocuments/publicdisplaydocumentpdf/?cote=env/jm/ mono(2000)7\& doclanguage $=$ en (accessed on 24 November 2015).

17. IACUC. Human Intervention and Endpoints for Laboratory Animal Species, 2011. Available online: http://www.upenn.edu/regulatoryaffairs/Documents/iacuc/guidelines/iacucguidelinehumaneendpoints-8\%2023\%2011.pdf (accessed on 24 November 2015).

18. European Union. Directive 2010/63/EU of the European Parliament and of the Council of 22 September 2010 on the Protection of Animals Used for Scientific Purposes, 2010. Available online: http:/ / eur-lex.europa.eu/LexUriServ/LexUriServ.do?uri=OJ:L:2010:276:0033:0079:en:PDF (accessed on 24 November 2015).

19. Toth, L.A.; Gardiner, T.W. Food and water restriction protocols: Physiological and behavioral considerations. Contemp. Top. Lab. Anim. Sci. 2000, 39, 9-17. [PubMed]

20. Roe, F.J. Historical histopathological control data for laboratory rodents: Valuable treasure or worthless trash? Lab. Anim. 1994, 28, 148-154. [CrossRef] [PubMed]

21. Malatova, Z.; Ahlers, I. Diurnal rhythm corticosterone in fasted rats. Endocrinol. Exp. 1977, 11, $241-247$. [PubMed]

22. Heiderstadt, K.M.; McLaughlin, R.M.; Wright, D.C.; Walker, S.E.; Gomez-Sanchez, C.E. The effect of chronic food and water restriction on open-field behaviour and serum corticosterone levels in rats. Lab. Anim. 2000, 34, 20-28. [CrossRef] [PubMed] 
23. Moscarello, J.M.; Ben-Shahar, O.; Ettenberg, A. Effects of food deprivation on goal-directed behavior, spontaneous locomotion, and c-Fos immunoreactivity in the amygdala. Behav. Brain Res. 2009, 197, 9-15. [CrossRef] [PubMed]

24. Iio, W.; Tokutake, Y.; Koike, H.; Matsukawa, N.; Tsukahara, T.; Chohnan, S.; Toyoda, A. Effects of chronic mild food restriction on behavior and the hypothalamic malonyl-CoA signaling pathway. Anim. Sci. J. 2015, 86, 181-188. [CrossRef] [PubMed]

25. Moran, G. Severe food deprivation: Some thoughts regarding its exclusive use. Psychol. Bull. 1975, 82, 543-557. [CrossRef] [PubMed]

26. Kalueff, A.V.; Zimbardo, P.G. Behavioral neuroscience, exploration, and K.C. Montgomery's legacy. Brain Res. Rev. 2007, 53, 328-331. [CrossRef] [PubMed]

27. Rex, A.; Voigt, J.P.; Voits, M.; Fink, H. Pharmacological evaluation of a modified open-field test sensitive to anxiolytic drugs. Pharmacol. Biochem. Behav. 1998, 59, 677-683. [CrossRef]

28. Bodnoff, S.R.; Suranyi-Cadotte, B.; Aitken, D.H.; Quirion, R.; Meaney, M.J. The effects of chronic antidepressant treatment in an animal model of anxiety. Psychopharmacology 1988, 95, 298-302. [CrossRef]

29. Britton, D.R.; Britton, K.T. A sensitive open field measure of anxiolytic drug activity. Pharmacol. Biochem. Behav. 1981, 15, 577-582. [CrossRef]

30. Rodgers, R.J.; Cao, B.J.; Dalvi, A.; Holmes, A. Animal models of anxiety: An ethological perspective. Braz. J. Med. Biol. Res. 1997, 30, 289-304. [CrossRef] [PubMed]

31. Pellow, S.; File, S.E. Anxiolytic and anxiogenic drug effects on exploratory activity in an elevated plus-maze: A novel test of anxiety in the rat. Pharmacol. Biochem. Behav. 1986, 24, 525-529. [CrossRef]

32. Cruz, A.P.; Frei, F.; Graeff, F.G. Ethopharmacological analysis of rat behavior on the elevated plus-maze. Pharmacol. Biochem. Behav. 1994, 49, 171-176. [CrossRef]

33. Carobrez, A.P.; Bertoglio, L.J. Ethological and temporal analyses of anxiety-like behavior: The elevated plus-maze model 20 years on. Neurosci. Biobehav. Rev. 2005, 29, 1193-1205. [CrossRef] [PubMed]

34. Rodgers, R.J.; Dalvi, A. Anxiety, defence and the elevated plus-maze. Neurosci. Biobehav. Rev. 1997, 21, 801-810. [CrossRef]

35. Schmitt, U.; Hiemke, C. Strain differences in open-field and elevated plus-maze behavior of rats without and with pretest handling. Pharmacol. Biochem. Behav. 1998, 59, 807-811. [CrossRef]

36. Hogg, S. A review of the validity and variability of the elevated plus-maze as an animal model of anxiety. Pharmacol. Biochem. Behav. 1996, 54, 21-30. [CrossRef]

37. Padovan, C.M.; Guimaraes, F.S. Restraint-induced hypoactivity in an elevated plus-maze. Braz. J. Med. Biol. Res. 2000, 33, 79-83. [CrossRef] [PubMed]

38. Korte, S.M.; de Boer, S.F. A robust animal model of state anxiety: Fear-potentiated behaviour in the elevated plus-maze. Eur. J. Pharmacol. 2003, 463, 163-175. [CrossRef]

39. Faul, F.; Erdfelder, E.; Lang, A.G.; Buchner, A. G* power 3: A flexible statistical power analysis program for the social, behavioral, and biomedical sciences. Behav. Res. Methods 2007, 39, 175-191. [CrossRef] [PubMed]

40. Rowland, N.E. Food or fluid restriction in common laboratory animals: Balancing welfare considerations with scientific inquiry. Comp. Med. 2007, 57, 149-160. [PubMed]

41. Armstrong, S.; Coleman, G.; Singer, G. Food and water deprivation: Changes in rat feeding, drinking, activity and body weight. Neurosci. Biobehav. Rev. 1980, 4, 377-402. [CrossRef]

42. Palou, M.; Sanchez, J.; Rodriguez, A.M.; Priego, T.; Pico, C.; Palou, A. Induction of NPY/AgRP orexigenic peptide expression in rat hypothalamus is an early event in fasting: Relationship with circulating leptin, insulin and glucose. Cell Physiol. Biochem. 2009, 23, 115-124. [CrossRef] [PubMed]

43. Gianotti, M.; Clapes, J.; Llado, I.; Palou, A. Effect of 12, 24 and $72 \mathrm{~h}$ fasting in thermogenic parameters of rat brown adipose tissue mitochondrial subpopulations. Life Sci. 1998, 62, 1889-1899. [CrossRef]

44. Dohm, G.L.; Tapscott, E.B.; Barakat, H.A.; Kasperek, G.J. Influence of fasting on glycogen depletion in rats during exercise. J. Appl. Physiol. Respir. Environ. Exerc. Physiol. 1983, 55, 830-833. [PubMed]

45. Bi, S.; Robinson, B.M.; Moran, T.H. Acute food deprivation and chronic food restriction differentially affect hypothalamic NPY mRNA expression. Am. J. Physiol. Regul. Integr. Comp. Physiol. 2003, 285, 1030-1036. [CrossRef] [PubMed]

46. Hurwitz, H.M.; Davis, H. Depriving rats of food: A reappraisal of two techniques. J. Exp. Anal. Behav. 1983, 40, 211-213. [CrossRef] [PubMed] 
47. Hadjimarkou, M.M.; Singh, A.; Kandov, Y.; Israel, Y.; Pan, Y.X.; Rossi, G.C.; Pasternak, G.W.; Bodnar, R.J. Opioid receptor involvement in food deprivation-induced feeding: Evaluation of selective antagonist and antisense oligodeoxynucleotide probe effects in mice and rats. J. Pharmacol. Exp. Ther. 2004, 311, 1188-1202. [CrossRef] [PubMed]

48. El Fazaa, S.; Somody, L.; Gharbi, N.; Kamoun, A.; Gharib, C.; Gauquelin-Koch, G. Effects of acute and chronic starvation on central and peripheral noradrenaline turnover, blood pressure and heart rate in the rat. Exp. Physiol. 1999, 84, 357-368. [CrossRef] [PubMed]

49. Li, J.B.; Wassner, S.J. Effects of food deprivation and refeeding on total protein and actomyosin degradation. Am. J. Physiol. 1984, 246, 32-37.

50. Deacon, R.M.; Rawlins, J.N. Hippocampal lesions, species-typical behaviours and anxiety in mice. Behav. Brain Res. 2005, 156, 241-249. [CrossRef] [PubMed]

51. Olszewski, P.K.; Ulrich, C.; Ling, N.; Allen, K.; Levine, A.S. A non-peptide oxytocin receptor agonist, WAY-267,464, alleviates novelty-induced hypophagia in mice: Insights into changes in c-Fos immunoreactivity. Pharmacol. Biochem. Behav. 2014, 124, 367-372. [CrossRef] [PubMed]

52. Rex, A.; Sondern, U.; Voigt, J.P.; Franck, S.; Fink, H. Strain differences in fear-motivated behavior of rats. Pharmacol. Biochem. Behav. 1996, 54, 107-111. [CrossRef]

53. Bert, B.; Fink, H.; Sohr, R.; Rex, A. Different effects of diazepam in Fischer rats and two stocks of Wistar rats in tests of anxiety. Pharmacol. Biochem. Behav. 2001, 70, 411-420. [CrossRef]

54. Inoue, K.; Zorrilla, E.P.; Tabarin, A.; Valdez, G.R.; Iwasaki, S.; Kiriike, N.; Koob, G.F. Reduction of anxiety after restricted feeding in the rat: Implication for eating disorders. Biol. Psychiatry 2004, 55, 1075-1081. [CrossRef] [PubMed]

55. Genn, R.F.; Tucci, S.A.; Thomas, A.; Edwards, J.E.; File, S.E. Age-associated sex differences in response to food deprivation in two animal tests of anxiety. Neurosci. Biobehav. Rev. 2003, 27, 155-161. [CrossRef]

56. Pego, J.M.; Sousa, J.C.; Almeida, O.F.; Sousa, N. Stress and the neuroendocrinology of anxiety disorders. Curr. Top. Behav. Neurosci. 2010, 2, 97-117. [PubMed]

57. Hatori, M.; Vollmers, C.; Zarrinpar, A.; DiTacchio, L.; Bushong, E.A.; Gill, S.; Leblanc, M.; Chaix, A.; Joens, M.; Fitzpatrick, J.A.; et al. Time-restricted feeding without reducing caloric intake prevents metabolic diseases in mice fed a high-fat diet. Cell Metab. 2012, 15, 848-860. [CrossRef] [PubMed]

58. Moberg, G.P.; Bellinger, L.L.; Mendel, V.E. Effect of meal feeding on daily rhythms of plasma corticosterone and growth hormone in the rat. Neuroendocrinology 1975, 19, 160-169. [CrossRef] [PubMed]

59. Patton, D.F.; Parfyonov, M.; Gourmelen, S.; Opiol, H.; Pavlovski, I.; Marchant, E.G.; Challet, E.; Mistlberger, R.E. Photic and pineal modulation of food anticipatory circadian activity rhythms in rodents. PLOS ONE 2013. [CrossRef] [PubMed]

60. Verwey, M.; Amir, S. Food-entrainable circadian oscillators in the brain. Eur. J. Neurosci. 2009, 30, $1650-1657$. [CrossRef] [PubMed]

61. Poulin, A.M.; Timofeeva, E. The dynamics of neuronal activation during food anticipation and feeding in the brain of food-entrained rats. Brain Res. 2008, 1227, 128-141. [CrossRef] [PubMed]

62. Nowland, M.H.; Hugunin, K.M.; Rogers, K.L. Effects of short-term fasting in male Sprague-Dawley rats. Comp. Med. 2011, 61, 138-144. [PubMed]

63. Johansson, A.; Fredriksson, R.; Winnergren, S.; Hulting, A.L.; Schioth, H.B.; Lindblom, J. The relative impact of chronic food restriction and acute food deprivation on plasma hormone levels and hypothalamic neuropeptide expression. Peptides 2008, 29, 1588-1595. [CrossRef] [PubMed]

64. Pirke, K.M.; Spyra, B. Catecholamine turnover in the brain and the regulation of luteinizing hormone and corticosterone in starved male rats. Acta Endocrinol. 1982, 100, 168-176. [CrossRef] [PubMed]

65. De Boer, S.F.; Koopmans, S.J.; Slangen, J.L.; van der Gugten, J. Effects of fasting on plasma catecholamine, corticosterone and glucose concentrations under basal and stress conditions in individual rats. Physiol. Behav. 1989, 45, 989-994. [CrossRef]

66. Chandler-Laney, P.C.; Castaneda, E.; Pritchett, C.E.; Smith, M.L.; Giddings, M.; Artiga, A.I.; Boggiano, M.M. A history of caloric restriction induces neurochemical and behavioral changes in rats consistent with models of depression. Pharmacol. Biochem. Behav. 2007, 87, 104-114. [CrossRef] [PubMed]

67. Johnston, A.L.; File, S.E. Sex differences in animal tests of anxiety. Physiol. Behav. 1991, 49, 245-250. [CrossRef]

68. Nasello, A.G.; Machado, C.; Bastos, J.F.; Felicio, L.F. Sudden darkness induces a high activity-low anxiety state in male and female rats. Physiol. Behav. 1998, 63, 451-454. [CrossRef] 
69. Warneke, W.; Klaus, S.; Fink, H.; Langley-Evans, S.C.; Voigt, J.P. The impact of cafeteria diet feeding on physiology and anxiety-related behaviour in male and female Sprague-Dawley rats of different ages. Pharmacol. Biochem. Behav. 2014, 116, 45-54. [CrossRef] [PubMed]

70. De Lorge, J.; Bolles, R.C. Effects of food deprivation on exploratory behavior in a novel situation. Psychol. Rep. 1961, 9, 599-606. [CrossRef]

71. Pierre, P.J.; Skjoldager, P.; Bennett, A.J.; Renner, M.J. A behavioral characterization of the effects of food deprivation on food and nonfood object interaction: An investigation of the information-gathering functions of exploratory behavior. Physiol. Behav. 2001, 72, 189-197. [CrossRef]

(C) 2016 by the authors; licensee MDPI, Basel, Switzerland. This article is an open access article distributed under the terms and conditions of the Creative Commons by Attribution (CC-BY) license (http:/ / creativecommons.org/licenses/by/4.0/). 